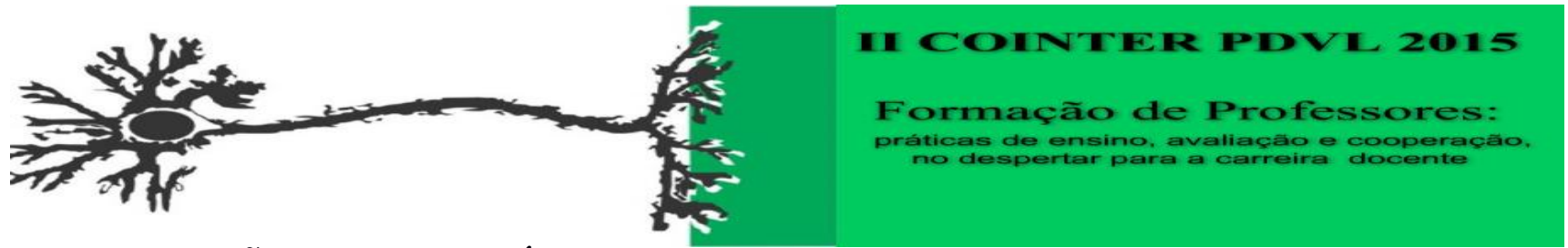

\title{
REFLEXÕES SOBRE PRÁTICAS AVALIATIVAS NOS AMBIENTES VIRTUAIS DE APRENDIZAGEM
}

\author{
Apresentação: Comunicação Oral
}

\begin{abstract}
Eliemerson de Souza Sales ${ }^{1}$; Inês Girlene dos Santos Monteiro ${ }^{2}$; Kilma da Silva Lima Viana ${ }^{3}$ Erick Viana da Silva ${ }^{4}$
\end{abstract}

\begin{abstract}
Resumo
A presente pesquisa teve como objetivo analisar os cursos oferecidos pelo PDVL na plataforma Learning do programa, no que se refere às formas de avaliação da aprendizagem no Ambiente Virtual de Aprendizagem - AVA e as práticas avaliativas dos professores. Como instrumentos de coletas de dados foram utilizados os materiais didáticos disponibilizados pelos professores na plataforma, os registros das discussões realizadas nos fóruns pelos professores e estudantes, além das avaliações realizadas pelos professores. A pesquisa revelou que as avaliações realizadas pelos professores dos cursos estão coerentes com os objetivos do PDVL, embora com professores atuando no formato de Rede de cooperação Internacional, o que evidencia a eficiência da Educação à Distância.
\end{abstract}

Palavras-Chave: PDVL, Educação à Distância, Práticas avaliativas.

\section{Introdução}

Partindo do ponto de vista de que a crescente transformação econômica e política, que o mundo vem passando nas últimas décadas têm influenciado e alterado bastante as relações de produção do conhecimento,

O desenvolvimento científico-tecnológico exige uma aprendizagem constante por parte de todas as pessoas, que precisam estar preparadas para aprender ao longo da vida, podendo intervir e adaptar-se a um novo cenário em constante evolução. Isso exige autonomia, criatividade e autocrítica na obtenção e na seleção de informações, assim como nos processos de aprendizagem (ZIDAN, 2011).

Nesse sentido, e, por conseguinte, ao desenvolvimento cientifico-tecnológico exige-se dos profissionais educadores uma visão de mundo que esteja relacionada a intervir de acordo com as demandas sociais e, sobretudo, com uma visão sólida acerca da Ciência, Tecnologia e Sociedade que tem sido uma área do conhecimento que tem trazido bastante contribuição para o desenvolvimento educacional e social no sentido de proporcionar uma formação de qualidade para

\footnotetext{
${ }^{1}$ Pós-Graduação em Educação de Ciências e Matemática - PPGECM, Universidade Federal de Pernambuco - Campus Caruaru, eliemersonsales@gmail.com

${ }^{2}$ Pós-Graduação em Educação de Ciências e Matemática - PPGECM, Universidade Federal de Pernambuco - Campus Caruaru, inesmonteiro777@gmail.com

${ }^{3}$ Profa. Drá., Instituto Federal de Pernambuco - Campus Vitória de Santo Antão, kilma.viana@vitoria.ifpe.edu.br

${ }^{4}$ Prof. MSc, Instituto Federal de Pernambuco - Campus Vitória de Santo Antão
} 
uma quantidade maior de pessoas, na perspectiva de atender as necessidades individuais e coletivas de todos que fazem parte da esfera educativa.

A plataforma de E-learning é uma instância da EAD apoiada nas tecnologias da internet"( LEMOS, 2003. p, 33) e, por isso, é um dos meios de comunicação que permite o desenvolvimento e fortalecimento da Rede de Cooperação Internacional que se dá a partir da troca de experiência entre parceiros de diversas instituições, tanto nacionais quanto internacionais e que participam de um programa chamado PDVL - Programa Internacional Despertando Vocações para Licenciaturas.

O Programa é uma experiência piloto, e foi inspirado em um projeto semelhante, voltado para as Engenharias, que foi desenvolvido pela Universidad de Mendoza (UM), em 2013, e teve a participação do Instituto Federal de Pernambuco (IFPE), tendo como objetivo desenvolver ações que auxiliem no despertar do interesse de estudantes do Ensino Médio para os cursos de Licenciatura, através da articulação de atividades de ensino, pesquisa e extensão e da troca de saberes entre a Academia e a Escola Básica, tendo como foco a formação do professor e as tecnologias educacionais, utilizando-se do formato de Rede de Cooperação Internacional.

A partir de pesquisas realizadas pelos GEPEC/IFPE - Grupo de Estudos e Pesquisas em Ensino de Ciências do Instituto Federal de Pernambuco observou-se que havia grande necessidade de fortalecer a troca de saberes acerca da democratização do Ensino e da desmistificação acerca do Ensino de Química, na perspectiva de fortalecer a formação dos licenciandos com a troca de saberes dos mesmos com os estudantes da Escola Básica.

A Avaliação não poderia ficar de fora desse contexto educativo, visto que a mesma é essencial para a tomada de decisões durante o processo, assim como diagnosticar os erros e acertos durante a construção do conhecimento, seja em ambientes virtuais de aprendizagem, ou no ensino presencial.

Destacamos sua importância no Ensino à Distância por permitir [...] destacar a relevância, a efetividade e o impacto de determinadas atividades com a finalidade de tomada de decisão (LAGUARDIA; PORTELA; VASCONCELOS, 2007) e intervenção no sentido de melhorar a qualidade do processo e rendimento dos estudantes durante o desenvolvimento do processo educativo. Assim, como em todo processo educativo, torna-se essencial que o professor conheça melhor os estudantes para que a Avaliação seja feita levando em consideração aspectos individuais.

Dessa forma, a presente pesquisa teve com o objetivo analisar os cursos oferecidos pelo PDVL na plataforma Learning do programa, no que se refere às formas de avaliação da aprendizagem no Ambiente Virtual de Aprendizagem - AVA e as práticas avaliativas dos professores. Para isso, buscamos (I) analisar as orientações contidas no PDVL sobre as práticas 
avaliativas no AVA e (II) analisar as práticas avaliativas adotadas pelos professores no AVA e suas relações com as orientações do PDVL e as especificidades do AVA.

\section{Fundamentação Teórica}

Nesta parte do artigo, o autor deve fazer uma exposição e uma discussão das teorias que foram utilizadas para entender e esclarecer o problema, apresentando-as e relacionando-as com a dúvida investigada. A fundamentação apresentada servirá de base para as análises dos dados, no momento da apresentação e discussão dos resultados.

\section{Breve histórico acerca da Educação à Distância no Brasil e a modalidade e-learning.}

O surgimento da Educação a Distância no Brasil como forma de ensino tem seu primeiro registro por volta do final do século XIX, aproximadamente na década de 1850 onde agricultores e pecuaristas recebiam correspondências que orientavam como plantar ou como cuidar do rebanho.

No Brasil a oferta do Ensino a Distância começou com escolas privadas que ofereciam cursos pagos por correspondências. Dentre as ferramentas que se destacam no histórico do desenvolvimento da Educação a Distância no Brasil, esta o Rádio que foi uma das ferramentas de maior propagação desta modalidade de Ensino utilizado com a iniciativa do SESC e SENAC e com a colaboração de algumas emissoras criaram a "Nova Universidade do Ar" com o objetivo de oferecer cursos gratuitos via rádio. "A aceitação foi positiva e em 1950 a Universidade do Ar chegou a atingir 318 localidades e oitenta mil alunos (BRASIL, 2008. p, 3).

Na década de 1960, o Movimento de Educação de Base (MEB), a Igreja Católica e o Governo Federal, fizeram uso do sistema radioeducativo, com o objetivo de promover a educação, a conscientização, a politização e a educação sindicalista (BRASIL, 2008. p, 3).

Ainda, por volta de 1970 um grupo de professores é enviado para a Inglaterra, fruto de um convênio do Governo Federal com a Inglaterra, onde foi criado um relatório que mudou bastante o pensamento acerca da Educação a Distância, surgindo desta forma um grande obstáculo à criação da Universidade Aberta e a Distância no Brasil. "Com o avanço dos meios de comunicação e a ampliação do acesso a internet, entre 1988 e 1991, processou-se a informatização e a reestruturação do Sistema de Teleducação" (BRASIL, 2008) que havia sido criado em 1976 e que fazia a utilização de correspondências, rádio e TV. Dentre os programas de Teleducação podemos destacar 
os telecursos oferecidos pela Fundação Roberto Marinho que até hoje é transmitido em redes de televisão.

Um marco inicial do registro da Educação a Distância nas Diretrizes Nacionais surge em 1995 quando o Departamento Nacional de Educação cria o setor dedicado exclusivamente as questões da EAD, o Centro Nacional de Educação a Distância - CEAD sendo de fato oficializada com a Lei n ${ }^{\circ}$ 9.394/96 que oficializa e reconhece a Educação a Distância com modalidade de ensino válida para todos os níveis de ensino.

Atualmente pode-se afirmar que Educação à Distância é regulamentada pelo Ministério da Educação - MEC por intermédio da Secretaria de Educação a Distância - SEED que,

[...] atua como um agente de inovação tecnológica nos processos de ensino e aprendizagem, fomentando a incorporação das Tecnologias de Informação e Comunicação (TICs) e das técnicas de educação a distância aos métodos didáticopedagógicos. Além disso, promove a pesquisa e o desenvolvimento voltados para a introdução de novos conceitos e práticas nas escolas públicas brasileiras. (BRASIL, 2008. p, 3)

Desta forma, e no que se refere à introdução de novos conceitos e práticas, a modalidade de educação a distância chamada e-learning se destaca por apresentar uma proposta que dialoga com todos os pressupostos propostos pelo Ensino à Distância na perspectiva de superar os desafios que são emergentes de uma sociedade que dispõe cada vez menos de tempo para dedicar-se às modalidades de ensino presencial por consequência da globalização em massa e também por consequência das atribuições profissionais e pessoas cotidianas.

Nesse caso, o e-learning pode prestar contribuições importantes na preparação dos recursos humanos das organizações para enfrentar esses desafios, pois em determinados pontos, apresenta vantagens importantes sobre os tradicionais treinamentos presenciais, com destaque para a rapidez na difusão de conhecimentos e informações, a facilidade para atingir um número maior de participantes e a possibilidade de atualização rápida de seu conteúdo (FERREIRA; VALÉRIO; SOUZA, 2010).

Nesse sentido, a modalidade e-learning destaca-se por permitir a troca de conhecimento e formação profissional em uma plataforma virtual pela qual ocorrem as discussões e troca de informações necessárias a formação pessoal e profissional. Em concordância com Filho (2011):

É verdade que a adoção do e-learning como ferramenta de desenvolvimento que transpõe barreiras geográficas, que causa uma ruptura nos limites das salas de aula, que muitas vezes evita o deslocamento de profissionais gera uma significativa diminuição nos gastos com educação [...] (FILHO, 2011.p, 13)

\section{Formação de professores sob a perspectiva da Educação à Distância.}


A formação de professores vem sofrendo várias modificações no que se refere à inserção de novos conteúdos a serem ensinados e aprendidos para que os profissionais tornem-se aptos a atuarem de forma qualificada no campo profissional.

Assim como já afirma a Lei de Diretrizes e Bases da Educação Brasileira - LDB de 20 de Dezembro de 1996,

A formação de profissionais da educação, de modo a atender aos objetivos dos diferentes níveis e modalidades de ensino e às características de cada fase do desenvolvimento do educando, terá como fundamentos: I - a associação entre teorias e práticas, inclusive mediante a capacitação em serviço; II - aproveitamento da formação e experiências anteriores em instituições de ensino e outras atividades.

Ressaltamos que estas modificações são frutos das novas demandas sociais, políticas e econômicas, além da importância do papel do professor tutor na modalidade de Ensino a Distância, o qual se faz necessário o domínio das bases teorias e metodologias de ensino na perspectiva de tornar o espaço educativo prático e dinâmico para que o público que recorre a esta modalidade que já dispõe de pouco tempo disponível possam administrar as atividades e planos de estudo propostos durante a formação à distância.

A Educação a Distância não pode ser considerada a parte das bases pedagógicas. Para que os profissionais possam atuar e desenvolver esta modalidade de ensino de forma significativa, as teorias pedagógicas e metodologias de ensino precisam estar presentes, sejam elas no fazer docente ou na prática docente. Ressaltamos que a adaptação das metodologias faz-se necessárias muitas vezes para que possam dialogar com as ferramentas disponíveis nesta modalidade.

A formação destes profissionais deve estar totalmente relacionada com as novas Tecnologias de Informação e Comunicação - TICs, estando-os aptos a integra-las a esta modalidade de ensino e saber fazer uso adequado e preciso.

Em um país de dimensões continentais e com enormes desigualdades e carências como o Brasil, a educação a distância é uma alternativa indispensável, conquanto seja garantido um padrão elevado de qualidade, com profissionais de alta competência, tanto na elaboração de conteúdos específicos quanto na assessoria pedagógica, com o uso de materiais instrucionais e de avaliação adequados. A EAD não deve ser implantada em programas isolados, precisa interagir com outras ações existentes. (Caderno Temático do Plano de Governo: uma escola para todos)

Desta forma pode-se destacar que além de ser essencial a participação e ação de professores na $\mathrm{EAD}$, os mesmos podem utilizar a Educação a Distância como forma de aperfeiçoamento profissional, pois, cada dia mais surge programas de aperfeiçoamento para professores que pretendem atuar nesta modalidade de ensino. 


\section{Metodologia}

O trabalho se desenvolveu com a abordagem quanti-qualitativa das respostas dos professores e discentes. Quanto aos procedimentos, trata-se de uma pesquisa exploratória em que foi feito o levantamento de dados e além do uso da pesquisa descritiva, em foi realizado analise, classificação e interpretação dos dados coletados.

a. Caracterização do Campo da Pesquisa. O campo de pesquisa foi o Ambiente Virtual de Aprendizagem - AVA da plataforma Learning, local onde foram oferecidos os cursos pelo PDVL.

b. Caracterização dos Sujeitos Participantes da Pesquisa. Os sujeitos da pesquisa foram 6 (seis) professores que ministraram, respectivamente, 5 (cinco) cursos e 59 (cinquenta e nove) estudantes que participaram dos fóruns durante esses cursos.

c. Aplicação dos Instrumentos da Pesquisa. Foram utilizados como instrumentos os materiais didáticos disponibilizados pelos professores na plataforma, os registros das discussões realizadas nos fóruns pelos professores e estudantes, além das avaliações realizadas pelos professores os quais foram analisados conforme Bardin (2011).

\section{Resultados e Discussão}

a. Analise da Proposta Avaliativa do PDVL.

No corpo do texto do programa Despertando Vocações para Licenciaturas, observamos que no que se referem à avaliação, as orientações não fazem menção à forma de avaliação dos cursos online da plataforma virtual. Toda discussão de avaliação é limitada às questões de gerenciamento de projeto com relação a pacotes e metas, sendo a mesma discutida de forma geral sem ser pormenorizada como verificamos no texto abaixo do documento do PDVL:

O acompanhamento e a Avaliação do projeto serão realizados através de reuniões semanais entre o coordenador e o bolsista extensionista, tendo como parâmetro os planos de trabalhos e as atividades realizadas na semana. Nesse acompanhamento, serão consideradas a apropriação do bolsista acerca dos aspectos a serem vivenciados no campo de ação, os objetivos alcançados, os entraves e êxitos obtidos.

Observamos que na reunião ordinária que tratou sobre avaliação dos cursos, foram discutidas junto à equipe central do programa as formas de avaliação, entretanto, cada professor já havia disponibilizado o plano do curso na plataforma, já haviam sido vivenciados todos os processos do curso e a maioria dos cursos já estavam em estado de conclusão. Foi disponibilizado, 
em alguns cursos, um formulário que tinha o objetivo de avaliar a proposta do curso e cada professor avaliava os estudantes da forma que achava conveniente avaliar.

Diante disso, verificamos que o PDVL necessita de um olhar mais direcionado para que os cursos possam ser avaliados de forma mais precisa garantido à participação de todos os evolvidos no curso para que as decisões não fiquem apenas nas mãos do professor, sendo dialogada e negociada com os estudantes.

Na versão 2015 do programa, ele traz alguns indicativos sobre avaliação dos cursos da plataforma virtual, mas, ainda assim, segundo a coordenação geral, as orientações acerca da avaliação dos cursos serão ainda definidas junto com a equipe de avaliação do programa.

b. Análise descritiva da proposta Avaliativa nos Cursos do Ambiente Virtual de Aprendizagem - AVA.

O “Curso 1” ministrado pelo Professor P1 apresentou como objetivo abordar as relações da química com a temática qualidade de água voltada para a prática docente no ensino médio.

Inicialmente o professor fez a apresentação do curso por meio de um vídeo no qual apresentava as novas perspectivas para o Ensino de Ciências, assim como disponibilizou no AVA o plano do curso. No que se refere à Avaliação, o plano do curso afirma que "a avaliação será contínua e processual, com instrumentos que se complementam e se conexa com o processo de ensino e aprendizagem".

O professor apresentou textos e vídeos para que os estudantes participassem dos fóruns de discussão com postagens referente aos temas trazidos nos textos, além de realizar réplicas das postagens dos estudantes, a continuar a discussão, no qual apenas 16 estudantes participaram. As outras duas atividades avaliativas também ocorreram através de fóruns de discussão com diminuição gradativa de participantes de 13 para 10 estudantes respectivamente.

O “Curso 2" ministrado pelo professor P2 e pelo professor P3 apresentou como objetivos desenvolver a capacidade de preparar experimentos demonstrativos de química, com objetos e materiais utilizados no dia a dia e contextualizar a prática com os conhecimentos teóricos de química, para serem aplicados em sala de aula.

No que se refere à Avaliação, no contrato pedagógico disponibilizado no AVA do curso está disposto: 
"Vocês serão avaliados conforme abaixo: Participação nos fóruns: 2 pontos. Resolução do questionário acerca dos experimentos: 4 pontos. Participação nos chats: 2 pontos. Apresentação de um vídeo seu sobre um experimento de baixo custo escolhido por você: 2 pontos".

Durante o curso ocorreram três fóruns de discussão, tendo no primeiro e no segundo a participação de 8 estudantes e no terceiro fórum a participação de 11 estudantes.

É importante ressaltar que em apenas uma semana o professor atribuiu aos estudantes a leitura de textos acerca de experimentos químicos, assim também como a conceituação teórica e prática presente em outro texto, além de 2 artigos para leitura. Ainda, o fórum e a entrega de questionário anexado pelo estudante e outro questionário digital. Por fim, os professores também realizaram a autoavaliação ao final do curso.

O “Curso 3" ministrado pelo professor P4 apresentou como objetivo "reconocer en la historia de la Química una estrategia de enseñanza que posibilita situar a la disciplina como una construcción cultural humana, donde los acontecimientos politicos-sociales, asi como tambien, las pasiones y controversias de los científicos juegan un rol importante a la hora de elaborar un modelo o una teoría."

A primeira atividade avaliativa teve o objetivo de fazer com que os estudantes realizassem discussões acerca de alguns textos que foram disponibilizados em que o professor solicitou, antecipadamente, aos estudantes que destacassem uma frase e realizassem a discussão das mesmas no fórum de discussão. Contudo, destacamos que algumas atividades exigiam dos estudantes a leitura de textos extensos no quais seriam essenciais para realizar as atividades propostas, como por exemplo, três textos de 10 páginas para serem lidos e a partir deles realizar duas atividades na mesma semana. Assim, na terceira semana do curso apenas 3 estudantes participaram no fórum para discutir sobre os temas, sem réplicas ou colocação do professor. Vale salientar que houve participação de 15 estudantes no primeiro fórum.

Segue abaixo imagens que permitem a comparação no que se refere a participação dos estudantes nos fóruns de discussão. 
Imagem 1: Print da tela do Primeiro Fórum de Discussão Curso 3

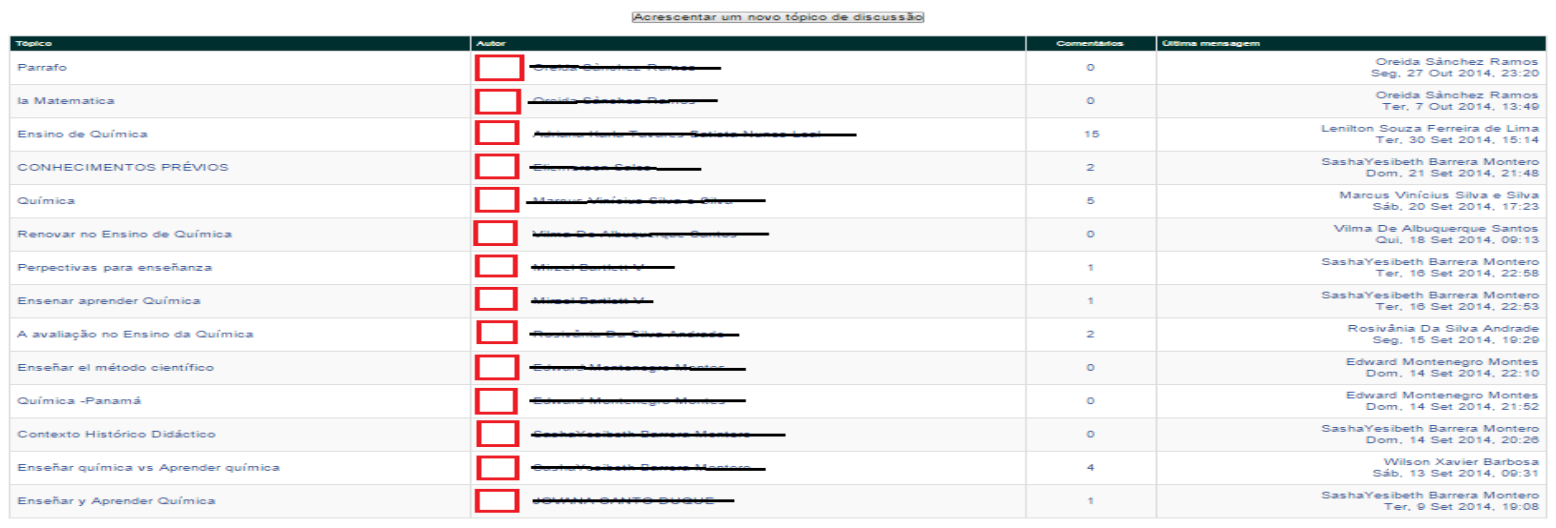

Imagem 2: Print da tela do último fórum de discussão Curso 3

Accescentar um novo topico de discussiac

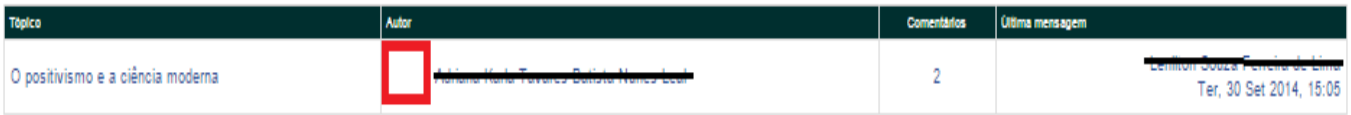

O “curso 4" ministrado pelo professor P5 apresentou como objetivo de discutir sobre as práticas avaliativas que estão presentes nas salas de aula das Ciências da Natureza, apresentando uma nova perspectiva de avaliação, que dialoga com a Teoria dos Construtos Pessoais e a Quarta Geração da Avaliação e que foi validada no chão da escola.

O professor deste curso deixou disponível a princípio o plano do curso no qual continha à proposta avaliativa, assim como em texto escrito na página inicial do curso. A avaliação será contínua e processual com instrumentos que se complementam e
se comunicam de forma que seja possível uma visão ampla e integral do processo
de ensino e aprendizagem, para que, a partir de seus resultados, o processo seja
repensado e refeito. Serão considerados a participação nos fóruns, chats, entregas
das atividades, e aprofundamento nas discussões. (Texto retirado do plano do
curso)

É importante ressaltar que o professor deste curso disponibilizou no inicio um fórum de discussão referente ao contrato didático em que os estudantes poderiam sugerir modificações no plano do curso ou na forma de avaliação, estabelecendo desta forma a negociação entre os estudantes e professor.

Inicialmente observou-se a participação de 15 estudantes no fórum referente ao contrato didático, de 50 inscritos no curso. Porém, pôde-se observar a diminuição de participação dos estudantes, uma vez que no penúltimo e último fóruns houve participação de 8 e 5 estudantes respectivamente. Vale salientar os que os textos disponibilizados pelo professor deste curso foram de fácil leitura e não extensos, o que parece ter sido elaborado cuidadosamente pelo professor, assim como os textos escritos na página inicial do curso. No entanto, embora os materiais 
disponibilizados não fossem extensos e o professor houvesse conduzido o curso de forma a não sobrecarregar os estudantes, o índice de evasão apresentou-se elevado.

O "curso 5" ministrado pelo professor P6 teve como objetivo dispor ao docente um conhecimento acerca das TICs mais utilizadas no desenvolvimento de conteúdos seja qual for a área de conhecimento, bem como ensiná-lo a utilizar uma ferramenta de AVA para que possa aplicar nas suas aulas.

O professor não apresentou a proposta avaliativa do curso, iniciando-o com bastantes textos tanto disponíveis em formato "pdf" como escritos na página do curso, sendo um deles com mais 500 páginas para leitura e discussão durante a semana. Observou-se que no primeiro fórum de discussão houve apenas a participação de 8 estudantes do curso, mantendo este quantitativo também no segundo fórum de discussão e apenas 6 participaram do último fórum de discussão.

O que se pode evidenciar deste curso é que única forma de atividade utilizada foi a leitura de textos e discussão nos fóruns.

a. Dado referente à evasão nos cursos do AVA.

Um tema muito importante e que tem preocupado os estudiosos desta área da Educação à Distância é a evasão dos cursos em Ambientes Virtuais de Aprendizagem que vem a ser um grande obstáculo para o desenvolvimento das ações propostas. Embora nos últimos anos o dados acerca da evasão tenha diminuído consideravelmente nos curso à distância, muito a de se preocupar para minimizar estes dados.

O Censo EAD (2012), afirmou que, “observou-se uma queda significativa da porcentagem de evasão informada pelos respondentes em todas as modalidades de cursos e das disciplinas no ano de 2012” (BRASIL, 2012).

Ainda, de acordo com o Censo EAD (2012),

Observa-se que a maior frequência de resposta dos participantes do Censo, independentemente do tipo de cursos oferecido, foram: falta de tempo para estudar e participar do curso $(23,4 \%)$, falta de adaptação à metodologia $(18,3 \%)$ e aumento da carga de trabalho $(15 \%)$.

Nesse sentido, é importante voltar à atenção para a metodologia utilizada no processo educativo na perspectiva de minimizar a evasão. É importante que a metodologia utilizada possa dialogar também com o tempo disponível dos estudantes para estudo.

Abaixo, apresentamos um gráfico que traz a relação de inscritos nos cursos com o número de concluintes em cada um deles: 
Gráfico 1. Relação de estudantes inscritos versus estudantes concluintes. Fonte: Própria

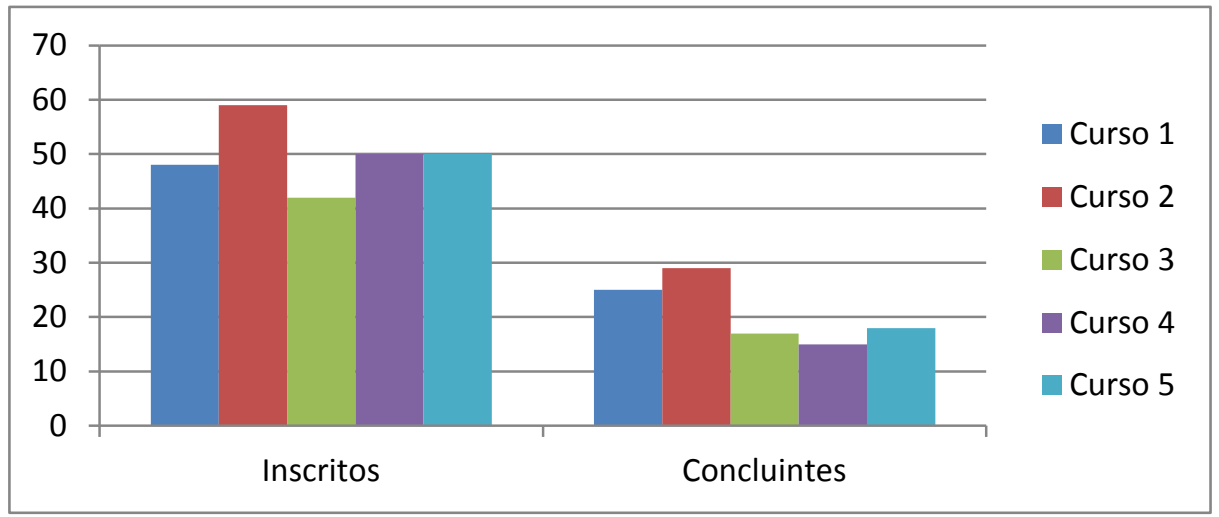

\section{Conclusões}

Sabe-se que no processo educativo à distância muito tem sido discutido no que se refere à aprendizagem dos estudantes que vivenciam este processo. Os debates sobre esse tema remetem que a Avaliação deve ser considerada processual, verificando as principais necessidades e ansiedades dos estudantes no sentido de melhor atender as expectativas dos mesmos, fazendo do ambiente virtual de aprendizagem um espaço confortável e dinâmico para o momento de estudo.

Foi possível verificar nessa pesquisa que alguns professores utilizaram materiais mais extensos do que outros e em contrapartida teve menor evasão em relação ao professor que materiais mais didáticos e de fácil leitura. De fato, há a necessidade de mais pesquisas em relação à evasão de estudantes, uma vez que estes se tornam mais ativos no processo de aprendizagem.

Verificamos que as atividades avaliativas convergem com o programa, uma vez que ocorre de forma processual, de acordo com as discussões apresentadas pelos estudantes e as réplicas dos professores, promovendo a construção da aprendizagem e a aproximação, embora que virtual, entre professor-estudante.

\section{Referências}

BARDIN, L. Análise de conteúdo. São Paulo: Edições 70, 2011, 229 p.

BRASIL. - EAD - Sua origem histórica, evolução e atualidade brasileira face ao paradigma da educação presencial. Relatório de Pesquisa. 2008. Disponível em: <http://www.abed.org.br/congresso2008/tc/552008104927AM.pdf> Acesso em: 12 de dezembro de 2014.

BRASIL. Balanço Geral da União. - Relatório. Ministério da educação/Secretaria de educação a distância - SEED, 2004. Disponível em: 〈http://portal.mec.gov.br/seed/arquivos/pdf/seed2004.pdf〉 Acesso em: 8 de novembro de dezembro de 2014. 
BRASIL. Censo EAD - Relatório Analítico da Aprendizagem a Distância no Brasil. Curitiba, 2012. Disponível em: <http://www.abed.org.br/censoead/censoEAD.BR_2012_pt.pdf> Acesso em: 8 dezembro de 2014.

BRASIL. Tecnologia na educação de professores a distância. S/a. Disponível em: <http://portal.mec.gov.br/seed/arquivos/pdf/4sf.pdf> Acesso em: 12 de janeiro de 2015.

FERREIRA, A.; VALÉRIO, J. N. G.; SOUZA, G. C. A Educação a Distância nas Organizações: a Percepção Sobre o e-learning em uma Grande Empresa Nacional. Revista EAD em Foco, Rio de Janeiro, n. $1, \quad$ vol.1, abr./out. 2010. Disponível em: <http://eademfoco.cecierj.edu.br/index.php/Revista/article/view/6/13> Acesso em: 12 de janeiro de 2015.

LAGUARDiA, J; PORTELA, M. C; VASCONCELOS, M. M. Avaliação em Ambientes Virtuais de Aprendizagem. Revista Educação e Pesquisa - São Paulo. v.33, n.3, p. 513-530, set./dez. 2007. Disponível em: <http://www.scielo.br/pdf/ep/v33n3/a09v33n3.pdf> Acesso em: 8 de dezembro de 2014.

LEMOS, D. da C. EDUCAÇÃO CORPORATIVA: Pesquisa de Soluções em elearning e Modelos de Universidades Corporativas. 2003. Dissertação (Mestrado) - Programa de Pós-Graduação em Engenharia de Produção, Universidade Federal de Santa Catarina, Florianópolis, 2003.

SILVA, L. I. Caderno Temático do Programa de Governo: Uma Escola do Tamanho do Brasil. São Paulo: Coligação Lula Presidente, 2003. Disponível em: <http://www.fpabramo.org.br/uploads/umaescoladotamanhodobrasil.pdf> Acesso em: 7 de outubro de 2014

ZIDAN, Vanda. As novas tecnologias de informação e comunicação e a educação a distância. Revista UNIABEU. Tecnologia, v. 4, p. 99-108, 2011. Disponível em: <http://www.uniabeu.edu.br/publica/index.php/RU/article/view/103/167> Acesso em: 12 dezembro de 2014 